\title{
Las estrellas en las metáforas lorquianas. Creación poética en las aulas
}

\author{
Pilar GARCÍA CARCEDO \\ Universidad Complutense \\ Didáctica de la lengua y la literatura \\ pcarcedo@edu.ucm.es
}

Recibido: octubre 2010

Poesía es la unión de dos palabras que uno nunca supuso que pudieran juntarse, y que forman algo así como un misterio.

(Federico $\mathrm{G}^{\mathrm{a}}$ Lorca)

Aceptado: marzo 2011

\section{RESUMEN}

El objetivo de este artículo es potenciar el aprendizaje creativo, la imaginación verbal y la cooperación entre los alumnos a través del contacto con la obra literaria de Federico García Lorca y mediante la escritura de metáforas en las aulas. Presentaremos, además, los resultados de las investigaciones en las que estamos desarrollando ejercicios de escritura creativa, a partir de modelos literarios, en las aulas de Primaria y en la Facultad de Educación.

Palabras clave: metáfora, escritura creativa, imaginación verbal, aprendizaje creativo, modelos literarios.

\section{Stars in Lorca's metaphors. Creating poetry in the classroom}

\begin{abstract}
The main goal of this paper is to promote creative writing, imagination and cooperation through contact with Lorca's literary works, as well as writing metaphors with the students. We also present the results of our research in which we are developing creative writing exercises, from literary models in Primary Education and at the University.

Keywords: Metaphor, Creative Writing, Verbal Imagination, Creative Learning, Literary Models, Evaluation.

Les étoiles dans les métaphores chez Lorca. Création poétique dans les salles de classe
\end{abstract}

\section{RÉSUMÉ}

L'objectif de cet article est de promouvoir la création littéraire, l'imagination et la coopération des étudiants par le contact avec l'œuvre littéraire de Federico García Lorca et par la création des métaphores. Nous présentons également les résultats de notre recherche, dans lesquels 
nous développons des exercices d'écriture créative, à partir de modèles littéraires dans l'enseignement primaire et dans la Faculté d'Éducation.

Mots-clés : Métaphore. Écriture créative. Imagination verbale. Apprentissage créatif. Modèles littéraires, Évaluation.

\section{SUMARIO}

1. Introducción. 2. Modelo literario: las metáforas en las obras completas de Lorca. 2.1. Las estrellas y el agua. 2.2. Imágenes negativas de las estrellas. 2.3. Las estrellas y la figura femenina. 2.4. Las más sorprendentes. 3. Escritura creativa: metáforas en las aulas. 3.1. E1 primer texto: "Nocturno" incluido en Suites. 3.2. El segundo texto: "Paisaje" del Libro de poemas: 3.3. Tercer texto: La prosa poética "Telégrafo". 4. Conclusiones. Referencias bibliográficas.

\section{INTRODUCCIÓN}

La metáfora se ha ganado un puesto indiscutible en el mismo núcleo generador del misterio poético y suele ser considerada como el más importante y frecuente de los tropos. De hecho, no se puede afrontar la escritura creativa sin tratar de desentrañar los enriquecedores mecanismos para generar metáforas. Por eso, este artículo constará de dos partes bien diferenciadas: en primer lugar, un análisis exhaustivo de los versos metafóricos relacionados con las estrellas en la obra de Federico García Lorca; y, en segundo lugar, sugerencias y ejercicios para desarrollar una secuencia didáctica basada en la creación de metáforas en las aulas tanto de la Facultad de Educación como de Educación Primaria.

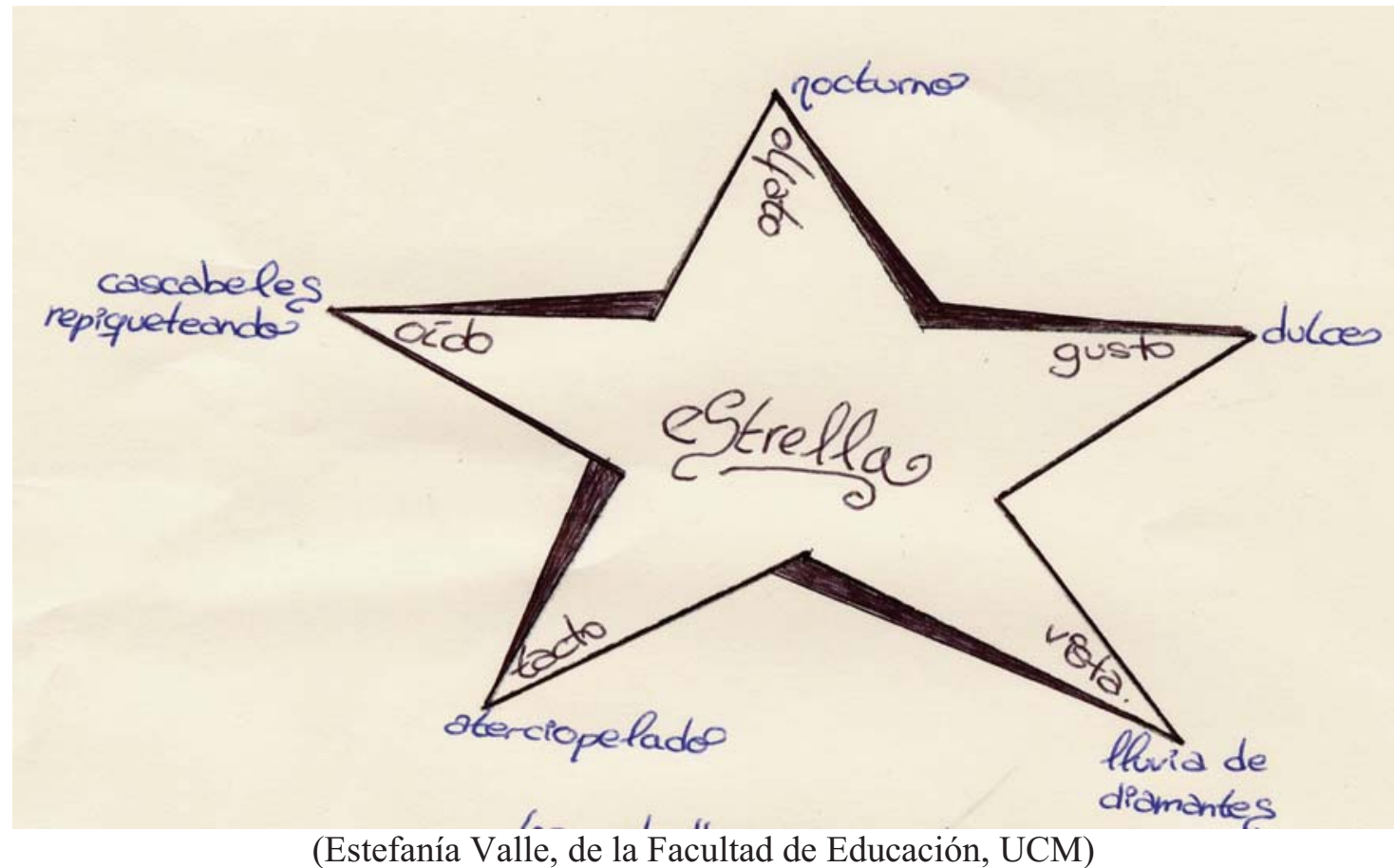


Leer un poema pensando en tomarlo como modelo literario nos convierte en cómplices con el escritor y nos lleva a observar con más detalle las peculiaridades estilísticas del texto y a interiorizar la técnica de recursos de tanta envergadura como la metáfora. La idea no es nueva, desde luego, ya hace veinte siglos Quintiliano escribía en sus Instituciones oratorias: "El arte consiste en gran parte en la imitación" $\left(\mathrm{X}, 2^{1}\right)$. La literatura ha estado siempre marcada por la intertextualidad, porque ningún texto se produce a partir de la nada, por generación espontánea, sino que todo texto está construido a partir de obras anteriores.

Hemos centrado este artículo en los mecanismos de uno de los recursos estilísticos más productivos, que debería aprender a utilizar cualquiera que empiece a escribir. La metáfora, que el DRAE define como "Tropo que consiste en trasladar el sentido recto de las voces a otro figurado, en virtud de una comparación tácita", etimológicamente significa "llevar más allá", conseguir trasladar el mundo concreto a otro plano. La gran fuerza poética de la metáfora reside en su capacidad de multiplicar de forma ilimitada el significado de las palabras, de modo que puedan llegar a describir lo desconocido, lo inefable, lo que en el fondo constituye siempre la gran aspiración del arte.

La que redacta estas páginas, estaba leyendo un artículo de Borges sobre la metáfora $^{2}$, cuando algunas de sus afirmaciones despertaron un sentimiento de intriga. Transcribamos la referencia de este gran autor: "me gustaría ocuparme de ciertas metáforas modelo, de ciertas metáforas patrón...la clásica comparación entre ojos y estrellas" (Borges, 2004: 39) "Si yo fuera un pensador atrevido (pero no lo soy, soy un pensador muy tímido, y voy avanzando a tientas) diría que solo existe una docena de metáforas" (Borges, 2004: 50). Resulta en todo caso curiosa esta estrategia borgiana de afirmar sin afirmar, sin comprometerse, que los modelos de metáfora son muy limitados.

Borges escoge precisamente la identificación modélica de las estrellas con ojos y lo ejemplifica con una de las primeras referencias que recuerda: "Desearía ser la noche para mirar tu sueño con mil ojos" (Platón, Antología griega). La afirmación de los limitados modelos metafóricos me parecía, desde luego, exagerada, aunque interesante. Así que me propuse analizar las metáforas relacionadas con las estrellas en la obra lorquiana; por ser este autor precisamente uno de los más reconocidos magos en la utilización de las imágenes.

\footnotetext{
${ }^{1}$ La Biblioteca de la Universidad de Sevilla (Pixelegis) ha digitalizado recientemente los dos tomos de esta obra, véase: http:/ / bib.us.es/ derecho/ recursos/ pixelegis/ areas/ miscelanea-ides-idweb.html

2 Borges, José Luis (2004): "La metáfora" en Arte poética. Seis conferencias., Barcelona, Crítica
} 


\section{MODELO LITERARIO: LAS METÁFORAS EN LA OBRA COMPLETA DE LORCA}

"Para que la metáfora tenga vida, necesita dos condiciones esenciales: forma y radio de acción. Su núcleo central y una redonda perspectiva en torno a él. El núcleo se abre como una flor que nos sorprende por lo desconocido, pero en el radio de luz que lo rodea hallamos el nombre de la flor y conocemos su perfume."

(Lorca, en su conferencia "La imagen poética")

Podríamos decir que la metáfora es una de las bases estilísticas principales de la poesía lorquiana. Bajo la influencia de Góngora entre otros, Lorca maneja metáforas muy arriesgadas: la distancia entre el término real y el imaginario es considerable; en ocasiones, usa directamente la metáfora pura y las imágenes pueden resultar difíciles de descifrar. A diferencia de cuando aparecen los dos términos de la identificación (real y evocado), caso en el que, como es bien sabido, se trata de una metáfora in praesentia o impura.

Podríamos comenzar por destacar en las imágenes lorquianas la deliberada intención de ilógica sorpresa, que, según sugería Carlos Bousoño en su Teoría de la expresión poética (1985: 146), refleja un hondo espíritu impresionista; corriente artística que viene a destruir una larga tradición de inmovilismo, según la que los atributos de las cosas eran inamovibles. En Lorca, sin embargo, ese subjetivismo impresionista nos conduce a sentir que la verdadera realidad de un objeto no está en el objeto mismo, es decir, en el objeto en sí, sino en el objeto en $m i^{4}$, en la impresión personal que cada uno, poeta o pintor, tiene de las realidades que le rodean. Así se aleja de las metáforas tradicionales para entrar en el ámbito del irracionalismo contemporáneo, como tendremos ocasión de comprobar a través del análisis de las imágenes lorquianas.

Las clasificaciones de metáforas son múltiples y se pueden realizar tanto desde criterios formales como desde criterios conceptuales (epíforas, por el parecido entre los términos identificados, frente a las diafóricas, que resultan más surrealistas, por ejemplo). Entre todas ellas, destacaremos algunas de las más originales en la obra lorquiana, antes de empezar a analizar todos los ejemplos concretos que hemos extraído de sus versos completos:

Las metáforas volitivas son alguno de los recursos lorquianos más originales, cuando las cosas y los seres quieren ser otros en un anhelo de totalidad existencial, en un acto de afirmación volitiva, como en el poema "Salomé y la luna" de Suites:

3 La conferencia se puede consultar completa en http://www.tinet.cat/ picl/libros/ glorca/g1001204.htm

${ }^{4}$ Aquí tratamos de resumir el irracionalismo verbal propio de la poesía contemporánea y directamente relacionado con el subjetivismo: "no importa el mundo sino la impresión que el mundo me produce” Bousoño, Op. Cit., p. 228. 
¡Oh sublime belleza, querer hacer de un beso una estrella! (O.C., 215)

Hay que llamar la atención también en las metáforas de Lorca sobre la transposición de lo audible en visión y de los visible en audible, son las llamadas metáforas sinestésicas:

Un poeta tiene que ser profesor en los cinco sentidos corporales. Los cinco sentidos corporales, en este orden: vista, tacto, oído, olfato y gusto. Para poder ser dueño de las más bellas imágenes tiene que abrir puertas de comunicación en todos ellos

(Lorca, en su conferencia "La imagen poética" ${ }^{5}$ )

Concibió la poesía y la vida como una gran metáfora, las estrellas como surtidores, como puñales, como espuelas o como mujeres amadas. Consiguió mirar la realidad como un incesante símbolo y transformar el lenguaje en metáfora de sí mismo. En, definitiva, el logrado estilo de la poesía lorquiana tiene uno de sus pilares en su utilización de las imágenes, porque, como decía Marcel Proust: "Sólo la metáfora puede dar una suerte de eternidad al estilo" ${ }^{\text {. }}$.

El lenguaje está hecho a base de imágenes, y nuestro pueblo tiene una riqueza magnífica de ellas. Llamar alero a la parte saliente del tejado es una imagen magnífica; o llamar a un dulce tocino del cielo o suspiros de monja, otras muy graciosas, por cierto, y muy agudas

(Lorca, en su conferencia "La imagen poética")

\subsection{Las estrellas y el agua}

Vamos ahora a analizar esa larga lista de metáforas creadas por Lorca que hemos extraído exhaustivamente de sus obras completas y sacaremos conclusiones sobre la tipología y la originalidad de sus imágenes.

En primer lugar, llama la atención que casi nunca utiliza Lorca la comparación modélica a la que hacía referencia Borges entre estrellas y ojos; sus metáforas son mucho más originales y los términos figurados con los que se relacionan los luceros son enormemente variados. Sólo en tres ocasiones encontramos la tópica identificación entre estrellas y ojos:

He visto las estrellas.

Subí al árbol más alto

que tiene la alameda

\footnotetext{
${ }_{6}^{5}$ La conferencia se puede consultar completa, referencia en la cita 3.

6 PROUST, Marcel (1920): Ensayo a propósito del "estilo" de Flaubert, véase: http://www.quedelibros.com/libro/34806/Ensayos-Literarios.html
} 
y vi miles de ojos

dentro de mis tinieblas. (O.C, 66)

E incluso en estas ocasiones, las variantes lorquianas difieren y no hacen referencia directa a los ojos, como por ejemplo:

Las estrellas entornan

sus párpados azules

una vez

y otra vez. $(O . C ., 200)$

El cielo se arrancó

la venda

y el dragón de los mil ojos

nos lame con sus lenguas

de viento. (O.C., 225)

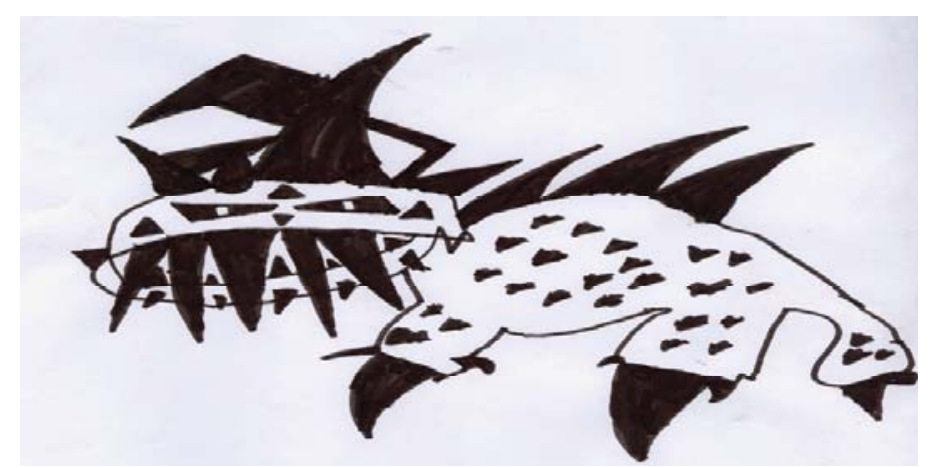

(Ilustración de Simón, 9 años)

Es más frecuente en Lorca la personal identificación entre las estrellas y el agua en sus diferentes formatos:

Y un torrente de cálidos luceros

brotó del seno que la noche guarda. (O.C., 159)

Tiene el mármol de la fuente

el beso del surtidor,

sueño de estrellas humildes. $(O . C, 71)$

Por el cauce de las ranas

o el cauce de los luceros

se irá nuestro amor cantando

la mañana del gran vuelo. (O.C., 205) 
Miro las estrellas

sobre el mar.

¡Las estrellas son de agua,

gotas de agua! (O.C., 210)

Aunque para el poeta parece evidente, en esta variante metafórica no es tan transparente la relación entre el término real y el figurado. El último ejemplo que acabamos de mencionar nos da una pista al hablar de "gotas de agua", que pueden ser tan numerosas y brillantes como las estrellas; pero no olvidemos que en otras ocasiones las identifica con torrentes, surtidores o cauces de agua continua. La relación es más clara cuando reúne las estrellas con las gotas de lluvia:

Sobre el olivar

hay un cielo hundido

y una lluvia oscura

de luceros fríos. (O.C., 306)

\title{
2.2. Imágenes negativas de las estrellas
}

En el imaginario lorquiano las estrellas no siempre son inocentes y hermosas, sino que con frecuencia se convierten en objetos punzantes y violentos, como las espuelas del caballo, cuyo parecido físico con las estrellas sí que es evidente:

El cielo, se les antoja, una vitrina de espuelas. (O.C., 443)

Lejos

una estrella

hiere al pavo real

del cielo. (O.C., 206)

En ocasiones esta metáfora se desarrolla, convirtiéndose la noche en un caballo negro que clava las estrellas-espuelas en los ijares:

\author{
En la luna negra \\ de los bandoleros, \\ cantan las espuelas (...) \\ Caballito negro. \\ ¿Dónde llevas tu jinete muerto? \\ La noche espolea \\ sus negros ijares \\ clavándose estrellas. (O.C., 365)
}


El violento término figurado no siempre tiene que ser una espuela, puede tratarse también de diamantes, de agujetas o de espadas:

El diamante de una estrella

ha rayado el hondo cielo. (O.C., 95)

Cornetines de cobre, clavan sus agujetas,

en la manzana rosa del cielo más lejano. (O.C., 479)

Será la Osa

Mayor, la arisca

fiera del cielo (O.C., 103)

Las estrellas pueden convertirse en armas blancas tradicionales como en los poemas "El emplazado" y "Árboles":

\section{Espadón de nebulosa}

mueve en el aire Santiago.

Grave silencio, de espalda,

manaba el cielo combado. (O.C., 440)

¿Árboles?

¿Habéis sido flechas

caídas del azul?

¿Qué terribles guerreros os lanzaron?

¿Han sido las estrellas? (O.C., 148)

Asimismo puede tratarse de una amenaza mucho más sorprendente o indeterminada, como en el famoso poema del Romancero gitano:

¡Preciosa, corre, Preciosa!

¡Míralo por dónde viene!

Sátiro de estrellas bajas

con sus lenguas relucientes. (O.C., 417)

O bien en las temibles estrellas colocadas por el demonio del poema "Los álamos de plata":

Tenemos que asomarnos

a la sombra del pecho,

y arrancar las estrellas que nos puso Satán. (O.C., 152) 
La relación formal entre las puntas de la estrella y otras partes, como los tentáculos del pulpo, puede conducirnos a esta desasosegante sustitución de los luceros por el oscuro octopus marino:

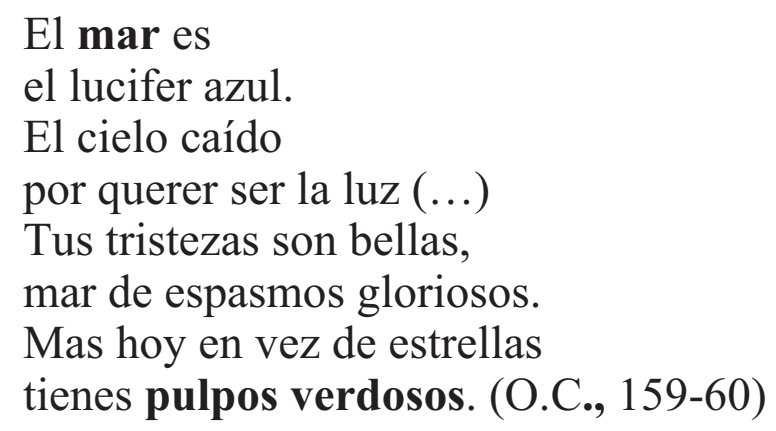

En esta última imagen las interrelaciones son aún más complejas, porque se parte de la identificación entre el cielo (estrellado) y el mar (como ya habíamos visto en muchas metáforas acuáticas), para llegar hasta el temido animal marino. No se trata, además, de una metáfora aislada, sino que esta relación la reencontramos en otros poemas. Como el que veremos a continuación, también complejo, por presentar una triple metáfora: Estrella-palmera-pulpo (tres elementos con claras concomitancias formales por los picos-hojas o palmas-tentáculos):

En el cielo la estrella y el pulpo abajo.

(La palmera de Satán y la palmera de Zoroastro.)

La estrella flota en el espacio.

El pulpo flota en el Mediterráneo. (O.C., 248)

Estrellas deformadas que producen desasosiego, como en estos versos del Primer Romancero gitano o en los siguientes de las Odas:

Noche de torsos yacentes

y estrellas de nariz rota (O.C., 446)

Honda luz cegadora de materia crujiente, luz oblicua de espadas y mercurio de estrellas anunciaban el cuerpo sin amor que llegaba (O.C., 466)

La complejidad del imaginario lorquiano nunca deja de sorprendernos, precisamente por el hecho de poder alternar la identificación del mismo objeto tanto con elementos figurados extremamente peligrosos o negativos como con otros de enorme inocencia, hermosura y sutileza. En mi opinión, esa dualidad variable es uno 
de los mayores logros de la poesía de Lorca. En la que las imágenes y las metáforas nunca mueren, es decir, nunca pierden fuerza por un uso excesivo y no llegan a lexicalizarse.

\subsection{Las estrellas y la figura femenina}

A modo de ejemplo, nada mejor que recordar los casos en que, después de haber utilizado las estrellas como símbolos del mal, aparecen en representación de la amada y del amor:

Ella era entonces para mí el enigma, estrella azul sobre mi pecho intacto. (O.C., 78)

Ella es luz hecha canto de ilusiones románticas $(\ldots)$ Miel de luna que fluye de estrellas enterradas. (O.C., 80)

- $\quad$ La estrella de mi amante que vive y muere.

- Estrellitas del cielo son mis quereres. (O.C., 107)

No es Lorca el primer ni el último poeta que ha identificado a las estrellas con muchachas, recordemos el antecedente de Juan Ramón en esta canción de Eternidades:

Las estrellas estaban sentadas todas, niñas desnuditas, meciendo sin parar, en el azul, las piernas, en fila, sobre el borde de los cielos.

Llegando yo, me daban, locas, con los pies en el alma, y me echaban riéndose, al día trastornado del despierto. (Jiménez, Libros de poesía, 1959: 645)

O bien, volviendo a Lorca, en "Tres estampas del cielo" (Suites), donde la metáfora más extensa se convierte en una elaborada alegoría:

Las estrellas no tienen novio. 
Todas las noches salen a las rejas

-joh cielo de mil pisos!-

y hacen líricas señas

a los mares de sombra

que las rodean.

Pero aguardar, muchachas,

que cuando yo me muera

os raptaré una a una

en mi jaca de niebla. (O.C., 207)

O bien en estos dos originales poemas de Suites en los que son niñas en peligro:

La osa mayor

da teta a sus estrellas

panza arriba.

Gruñe

Y gruñe.

Gruñe

y gruñe.

¡Estrellas niñas, huid;

estrellitas tiernas! (O.C., 201)

La primera estrella.

Todo mira hacia Venus

Y ella como una niña

que se cae en el aljibe

tiembla y tiembla

como diciendo:

¿Volveré mañana? (O.C., 225)

Las estrellas

se están desnudando.

Camisas de estrellas

caen sobre el campo. (O.C., 232)

Estas identificaciones positivas de las estrellas se producen cronológicamente en un momento anterior, en las primeras obras lorquianas: Libro de poemas y Suites. Obras iniciales en las que aparecen la mayoría de las metáforas en las que las estrellas se relacionan con la amada y con otros elementos figurados de gran belleza, como los cisnes de plata de este fragmento del poema "El diamante", o la cama del niño del segundo ejemplo: 
Cazadores extrahumanos

están cazando luceros,

cisnes de plata maciza

en el agua del silencio. (O.C., 95)

Pero el niño futuro

nos dirá algún secreto

cuando juegue en su cama

de luceros. (O.C., 101)

En estas primeras obras, cuando las estrellas tienen implicaciones negativas es porque están apagadas, como en este símil:

Dice la tarde:

"¡Tengo sed de sombra!"

Dice la luna: "Yo sed de luceros". (O.C., 98)

Hoy mi pecho está reseco

como una estrella apagada. (O.C., 99)

Las estrellas apagadas

llenan de ceniza el río

verdoso y frío (...)

Una estrella le hace burla

desde su casa de añil

infantil. (O.C., 111)

\subsection{Las más sorprendentes}

Creo que a lo largo de todo el trabajo ha quedado suficientemente demostrada la originalidad de las metáforas lorquianas, que, desde luego, no se limitan al modelo o patrón mencionado por Borges. Añadiremos ahora algunos otros ejemplos esporádicos, casi todos del Libro de poemas, en los que Lorca no se repite nunca, e idenfica las estrellas con los elementos más sorprendentes. Enumero los cuatro primeros casos porque su originalidad es suficientemente explícita y representativa del irracionalismo contemporáneo que comentaremos a continuación:

Clara estrella azul,

ombligo de la aurora. (O.C., 122)

Guárdate tu cielo azul, que es tan aburrido, el rigodón de los astros $y$ tu infinito, 
que yo pediré prestado

el corazón a un amigo. (O.C., 125)

¿Buscáis la azul limosna

del cielo moribundo?

¿un céntimo de estrella? (O.C., 131)

Es la granada olorosa

un cielo cristalizado.

(Cada grano es una estrella,

cada velo es un ocaso.) (O.C., 141)

En el original poema "Ritmo de otoño", también del Libro de poemas, es el viento protagonista el que, en primera persona, se identifica con las estrellas:

En la tristeza húmeda

el viento dijo:

- Yo soy todo de estrellas derretidas, sangre del infinito. (O.C., 167)

Y en este otro de Canciones, en el que las estrellas se convierten en espejos que reflejan la propia imagen del poeta multiplicada hasta la eternidad:

¿Por qué nací entre espejos?

El día me da vueltas.

Y la noche me copia

en todas sus estrellas. (O.C., 411)

En todos estos ejemplos estamos observando la transformación de la metáfora tradicional en lo que Carlos Bousoño (1985:228) ha definido como imagen visionaria, donde la relación de semejanza entre los términos no es ya una similitud física objetiva, sino que tiene que ver con la intensidad del sentimiento subjetivo que ambos objetos provocan al poeta. En la imagen visionaria no hay una relación sensorial entre los dos términos, como en el ejemplo de Bousoño: "un pajarillo es como un arco iris", donde "el plano fantástico "arco iris"...establece el grado de nuestro sentimiento ante un pajarillo". Viene a decirnos el poeta que la emoción es de la misma clase que un arco iris suele originar en nuestro ánimo, o, en nuestro caso, que "el viento" es "sangre del infinito" "todo de estrellas derretidas", términos que, desde luego no presentan una similitud formal.

Así veremos las imágenes lorquianas más surrealistas entre las pocas metáforas de estrellas que encontramos en Poeta en Nueva York: 
Y el que huye con el corazón roto encontrará por las esquinas al increíble cocodrilo quieto bajo la tierna protesta de los astros.

Que se entere la luna

y esa noche de rocas amarillas

que ya se fue la vaca de ceniza. (O.C., 543)

¡Pronto! ¡Los bordes! ¡Deprisa! Y croaban las estrellas tiernas,

...que no desemboca. (O.C., 544)

Cuando la luna salga

las poleas rodarán para turbar el cielo;

un límite de agujas cercará la memoria

y los ataúdes se llevarán a los que no trabajan. (O.C., 564)

Imágenes visionarias, sin una relación de semejanza objetiva, se presentan también en nuestro lenguaje más coloquial e intuitivo, por ejemplo, cuando alguien exclama "esa chica está como un queso o como un camión", no hay, desde luego, ningún parecido físico entre la mujer y el queso o entre la mujer y el camión, sino que su belleza ha producido al observador un efecto tan grande como el del paso de un camión o el sabor del queso. Es por lo que este tipo de imágenes visionarias no están tampoco ausentes del lenguaje infantil y la creatividad del imaginario del niño es mayor que la de los adultos, como veremos en la segunda parte de este artículo.

Así también es original Lorca en la metáfora volitiva del poema significativamente titulado "Deseo", en el que las pretensiones amorosas del yo poético se entrecruzan con las de la estrella:

Ni la estrella que quiere

ser hoja.

Una enorme luz

que fuera

luciérnaga

de otra,

en un campo de

miradas rotas. (O.C., 151)

O en este otro poema volitivo de Suites:

Hay montañas

que quieren ser

de agua,

y se inventan estrellas

sobre la espalda. (O.C., 232) 
Lorca no deja de combinar técnicas novedosas para la elaboración de las metáforas; en los siguientes versos de "Pórtico", de Suites, y "Las seis cuerdas", del Poema del cante jondo, será un agente externo, en este caso la araña, el que se encargará de tejer la transformación:

\author{
Una araña \\ inmensa \\ hace a la luna \\ estrella. (O.C., 197) \\ La guitarra, \\ hace llorar a los sueños (...) \\ Y como la tarántula \\ teje una gran estrella \\ para cazar suspiros \\ que flotan en su negro \\ aljibe de madera. (O.C., 322)
}

O bien en el poema "Remanso" de Suites donde la personificación nos conduce por el camino del erotismo hacia la estrella fugaz:

\author{
Una luciérnaga \\ rueda monte abajo, \\ y una estrella se corre. (O.C., 196)
}

Asimismo, en el breve poema "El murciélago" en el que la estrella se convierte en amante del pájaro de la noche:
El murciélago
elixir de la sombra, verdadero amante de la estrella,
muerde el talón del día. (O.C., 217)

Finalmente, llama la atención que Lorca casi no utiliza en toda su obra la imagen de las estrellas como flores o plantas, que es una de las más frecuentes en literatura; recordemos, por ejemplo, el maravilloso poema de Darío dedicado a Margarita Debayle:
Y ella dice: - «No hubo intento;
yo me fui no sé por qué.
Por las olas por el viento
fui a la estrella y la corté» (...)
Y así dice: — «En mis campiñas
esa rosa le ofrecí; 
son mis flores de las niñas

que al soñar piensan en mí».

(DARÍO, Poesías completas, 1954: 54)

O bien el famoso poema de amor de Pablo Neruda:

Los pájaros nocturnos picotean las primeras estrellas

que centellean como mi alma cuando te amo.

Galopa la noche en su yegua sombría

desparramando espigas azules sobre el campo.

(Neruda, Obras completas, 2005: 183)

Queremos insistir en todo caso en la originalidad de las metáforas lorquianas, que, como hemos confirmado, van mucho más alla del patrón sugerido por Borges, puesto que aquellas en las que las estrellas se relacionan con ojos son las menos frecuentes. También nos ha llamado la atención que las metáforas de estrellas están mucho más presentes en las primeras obras que en las últimas. En todo Poeta en Nueva York, por ejemplo, no hay más que cinco casos, mientras que en Libro de poemas son veintiocho y en Suites son veintisiete las ocasiones en que Lorca juega con las estrellas en sus metáforas. Entre la menos conocida Poesía varia hemos encontrado algunas prosas poéticas, de las que hablaremos entre las actividades de escritura creativa, y "El poema de mi cuarto" en el que el yo poético termina persiguiendo las estrellas que tanta trascendencia han resultado tener a lo largo de su obra:

Las ranas viejas piden ojos

a las estrellas del silencio (...)

Yo llego a la ventana.

Beso el farol (¡mi corazón!), me siento

$\mathrm{Y}$ escuchando el rodar de los tranvías

hago mi cacería de luceros. (O.C., 654)

En cuanto a los términos figurados con los que Lorca realiza las identificaciones, es muy frecuente que se trate de elementos negativos, violentos o desasosegantes (espuelas, espadas, pulpos, etc.) La complejidad del imaginario lorquiano, sin embargo, alterna la identificación del mismo objeto con otros elementos de gran hermosura y sutileza. Hemos destacado esa dualidad variable como uno de los mayores logros de la poesía de Lorca, por el que las imágenes y las metáforas nunca mueren, es decir, nunca pierden fuerza por un uso excesivo y no llegan a lexicalizarse. En las siguientes páginas trataremos de aprovechar la riqueza de este modelo literario para el desarrollo de las competencias relacionadas con la escritura creativa en las aulas. Para ello es importante que los estudiantes se acerquen a la poesía y aprendan a comprenderla y a analizarla, recomendamos la página web que 
hemos creado en el grupo de investigación LEETHi para facilitar este proceso de aproximación a la poesía?

\section{ESCRITURA CREATIVA: METÁFORAS EN LAS AULAS}

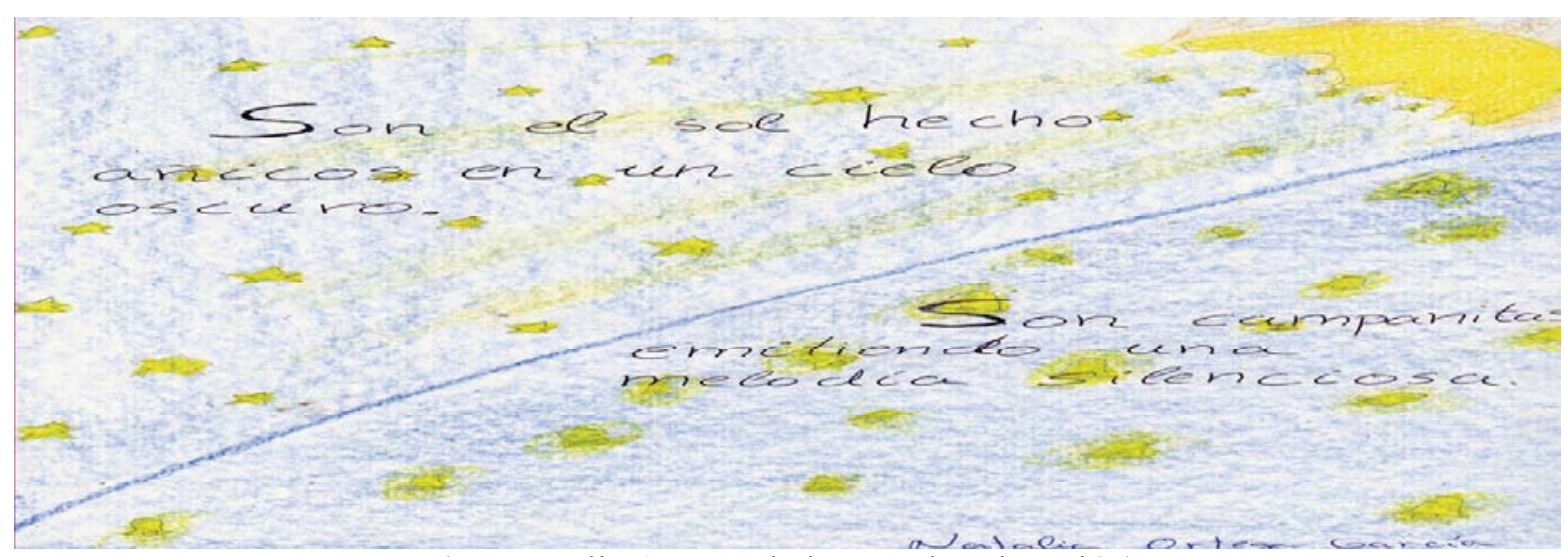

(Por Natalia Ortega, de la Fac. de Educación)

Un proyecto de escritura creativa comienza por la preparación una secuencia didáctica, que parte de la lectura y análisis de una serie de textos de referencia, la literatura como fuente inagotable de modelos, técnicas y recursos. La práctica de la escritura conlleva un desarrollo simultáneo de hábitos lectores y su éxito se construye sobre una adecuada selección de los textos que se van a ofrecer a los alumnos (calidad literaria, adecuación a las necesidades e intereses de los destinatarios, etc.) En el caso de la poesía, los estudiantes más mayores suelen tener cierta prevención, creen que no la entienden o que es muy difícil, pero los más pequeños, los alumnos de Primaria por ejemplo, se ven especialmente atraídos por el ritmo y la musicalidad de este género literario, no tienen prejuicios y es el mejor momento para mantener el disfrute poético en las aulas.

Contamos con una ya larga tradición de talleres de escritura creativa, que desde las vanguardias o el Oulipo hasta los Ejercicios de estilo de Raymond Queneau (1987), o al momento en que se introdujeron estos talleres en la educación escolar con Gianni Rodari y su Gramática de la fantasía (2002), publicada por primera vez en 1973, pero de absoluta actualidad para trabajar en las aulas de hoy en día. Muchos talleres de escritura posteriores quedarán para siempre deudores de las propuestas de Rodari; en

\footnotetext{
${ }^{7}$ Véanse las páginas creadas y gestionadas por el Grupo LEETHI (Literaturas Españolas y Europeas del Texto al Hipertexto) en las que pretendemos favorecer la capacidad crítica y la autonomía del lector, tanto en cuanto a la lectura e interpretación de los textos y las antologías propuestas, como para la búsqueda, selección y organización de la información existente en Internet:
}

- Guías de lectura: http://www.ucm.es/info/guias - LEETHI: http:www.ucm.es/info/leethi 
Francia Duchesne y Leguay, en España tenemos que agradecer, por ejemplo, talleres como los de Esperanza Ortega, Victor Moreno, Federico Martín Nebras, Felicidad Orquín, Ana Pelegrín y un largo etc. en los que junto a innumerables sugerencias de ejercicios de escritura creativa para las aulas, apuestan por la necesidad de una mayor presencia de la escritura creativa en los currículos. Algunos se han centrado en la escritura poética y han dedicado apartados a la creación metafórica, como es el caso de Victor Moreno. Siguiendo su ejemplo, vamos ahora a presentar las experiencias que estamos desarrollando, durante el curso 2010-2011, en las aulas de la Facultad de Educación en la asignatura optativa de "Lectura y escritura creativa" perteneciente al nuevo Grado de Magisterio de Primaria.

La actividad va a consistir en la lectura y análisis de las metáforas lorquianas y la posterior creación de metáforas por parte de los alumnos. El estudiante adulto tiene más trabajo que el niño a la hora de construir metáforas originales, pues ha de olvidarse de los usos ya solidificados, aprender a desandar el camino que lleva a una metáfora cotidiana como "carne de gallina" y luego utilizar esos recursos para volver patente la libertad que da el lenguaje. Los niños se dejan llevar por la intuición y son más imaginativos a la hora de inventar símiles o relaciones metafóricas; por eso, los estudiantes de magisterio pueden guiarse por los modelos y tener en cuenta las distintas fases de un proceso de escritura.

La planificación es la primera fase imprescindible de la escritura creativa, para ello los estudiantes deben ir haciéndose conscientes de que el género poético entraña sus propias reglas.

Hay que utilizar un lenguaje cuidado y polisémico, repleto de sugerencias, la poesía es connotación y transmite muchas más emociones de una manera inconsciente de las que transmite, por ejemplo, un texto expositivo. De ahí que resulte imprescindible familiarizarse con los mecanismos de recursos estilísticos como la metáfora antes de escribir.

También hay que tener en cuenta un aspecto que los escritores nóveles tienden a olvidar: la revisión y corrección de lo escrito es una fase final ineludible en cualquier proceso de escritura. Conviene escribir un borrador y varias versiones sucesivas (el profesor evaluará la evolución de todo el proceso, recogiendo las diferentes versiones).

Las actividades propuestas en las aulas de la Facultad de Educación han sido las siguientes:

1- En primer lugar, se les ha pedido a los estudiantes que creen libremente una serie de metáforas relacionadas con las estrellas, antes de leer los poemas lorquianos.

2- En segundo lugar, se les sugiere que creen una lista de objetos, plantas, animales o incluso sentimientos que les parezca que tienen alguna relación con las estrellas. 
3- Se puede ampliar la lista anterior por medio de un mapa conceptual o constelación de palabras ${ }^{8}$, en el que las estrellas ocupen el lugar central y alrededor se organicen todos esos conceptos divididos en cinco grupos: los cinco sentidos.

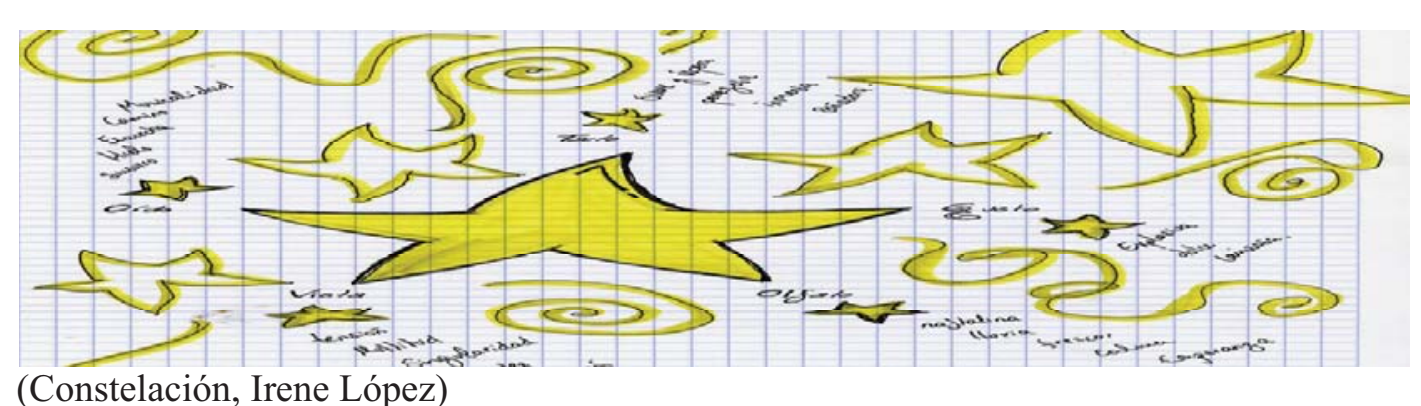

(Constelación, Irene López)

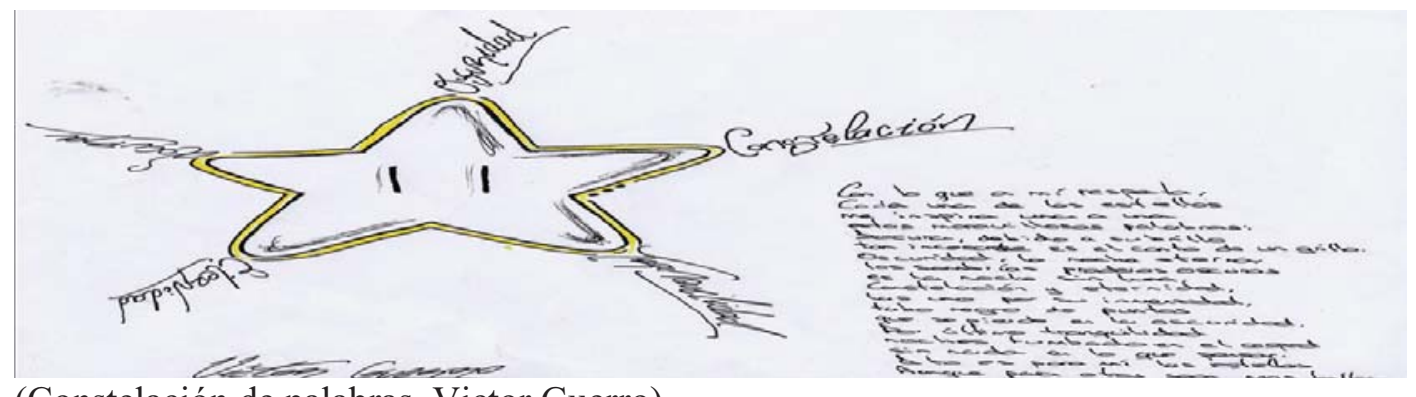

(Constelación de palabras, Victor Guerro)

4- Si las listas y constelaciones son demasiado limitadas, es el momento de leer las metáforas lorquianas y ver que la originalidad puede primar sobre la lógica en la poesía contemporánea.

5- Se han propuesto actividades creativas, de transformación y reescritura de textos, en base a ciertas metáforas lorquianas concretas (presentamos los versos seleccionados y las actividades en las siguientes páginas)

6- A continuación, se realizará una tipología formal de las distintas maneras de presentarse de las metáforas (con el verbo ser, con la preposición "de", etc.) Los alumnos crearán metáforas siguiendo cada una de las modalidades.

7- Después, se ampliarán las metáforas, dotándolas de un cierto contexto, y se crearán pareados con rima.

8- Finalmente, se unirán los pareados de varios alumnos, por grupos, y se retocarán para crear poemas colectivos.

9- Por último, se diseñarán actividades similares, pero más sencillas, para crear metáforas en las aulas de Primaria.

\footnotetext{
${ }^{8}$ Para profundizar sobre este método remitimos a Timbal-Duclaux (2004: 99 y stes)
} 
A continuación podemos ver algunas de las metáforas creadas libremente por los alumnos de la Factultad de Educación. Las dos primeras remiten a los ojos, confirmando, esta vez sí, la afirmación borgiana:

Las estrellas son los ojos

que me miran sin cesar.

(Marianela Vega)

Y las estrellas dormirán

cuando tus ojos vuelvan a abrirse.

( Rocío Forés)

Grandes caramelos de limón

(Clara Díaz)

Las estrellas son las lágrimas de mi niña

en una noche de primavera.

Son sus carcajadas una mañana de verano.

(Beatriz Bautés)

Las luciérnagas de la noche

vecinas de la luna.

Los lunares del cielo.

Las esperanzas de los soñadores.

(Javier Izaga)

Mil diamantes hasta el amanecer

en la cristalizada noche oscura.

(Erika Cazorla)

Eres la estrella polar que guía mi rumbo en la noche

(Yubitsa Broughton)

Lágrimas derramadas por la luna

triste ante la huida del sol.

(Sheila Puerta)

Algunas, entregadas después de escuchar los versos lorquianos, buscan especialmente la originalidad:

Caspa que cae sobre el hombro de un señorito en Marbella, perlas del mar profundo, tesoros de mundos lejanos, tan cerca de nuestras mentes, tan lejos de nuestras manos.

(Arturo Garrido) 
A continuación, presentamos los tres textos lorquianos que hemos seleccionado como modelos para las actividades de transformación textual y re-escritura en las aulas de la Facultad de Educación. Los hemos ido trabajando en este orden de dificultad creciente, desde el primer poema, en el que solo había que completar algunas palabras (y que se ha utilizado también en las aulas de Primaria), hasta la prosa poética final que entraña metáforas concatenadas de forma alegórica y por lo tanto más compleja:

\subsection{El primer texto: "Nocturno" incluido en Suites:}

Miro las estrellas

sobre el mar.

¡Las estrellas son de agua,

gotas de agua! (O.C., 210)

A los alumnos se les presentará una segunda estrofa en la que tienen que completar los versos con otros términos de comparación, de la siguiente forma:

Miro las estrellas

sobre

¡Las estrellas son de

Algunos resultados en las aulas han sido los siguientes:

Miro las estrellas

Sobre el fuego .

¡Las estrellas son de aire,

chispitas de aire!

Miro las estrellas

sobre el sol.

¡Las estrellas son de fuego,

llamas de fuego!

Miro las estrellas

sobre el cielo .

¡Las estrellas son de hielo,

cubitos de hielo!

Por último, se leerá el poema lorquiano completo, en cuya segunda estrofa también se realizaba una variación sobre el mismo tema similar a la que hemos desarrollado en las aulas: 


\section{NOCTURNO}

Miro las estrellas

sobre el mar.

¡Las estrellas son de agua,

gotas de agua!

Miro las estrellas

sobre mi corazón.

¡Las estrellas son de aroma,

núcleos de aroma!

Miro la tierra

llena de sombra

$$
\text { (O.C., 210) }
$$

3.2. El segundo texto pertenece a "Paisaje" del Libro de poemas:

Las estrellas apagadas

llenan de ceniza el río

verdoso y frío.

La fuente no tiene trenzas.

Ya se han quemado los nidos

escondidos.

Las ranas hacen del cauce

una siringa encantada

desafinada.

Sale del monte la luna, con su cara bonachona de jamona.

Una estrella le hace burla

desde su casa de añil

infantil (...) (O.C., 111)

En este caso la actividad consiste en continuar la descripción del paisaje nocturno con otras estrofas que, además de incluir metáforas, respeten la rima de las de Lorca, es decir, en las que los dos versos finales mantengan una rima consonante $\mathrm{y}$, si es posible, sean de pie quebrado (el segundo octosílabo y el último tetrasílabo). Se 
puede hacer de forma libre o, si les resulta difícil, sugerir las palabras en posición de rima en el poema lorquiano:



Veamos una selección de los resultados, en la versión libre de la actividad, que consistía en continuar el paisaje nocturno de Lorca manteniendo la rima consonante en los dos últimos versos de cada estrofa:

Las aves nocturnas abren la mañana de los sueños, de sus mil dueños.

El viento canta a la noche entre las ramas y hojas verdes y rojas.

La luna con las estrellas, cansada, desaparece, porque amanece. (Natalia Ortega)

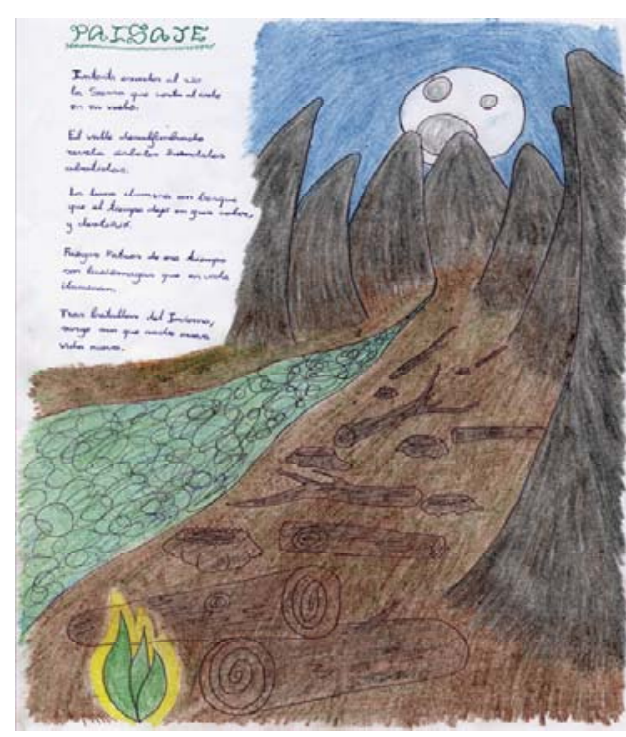

Intenta esconder al río la sierra que corta al cielo en su vuelo.

El valle desalfombrado revela árboles hundidos abatidos.

La luna ilumina un bosque (...) (Texto e ilustración de L. Antonio Fernández) 


\subsection{Tercer texto: La prosa poética "Telégrafo"}

La estación estaba solitaria...Yo me tumbé cara al cielo y me fui sin pensar a un raro país donde no tropezaba con nadie, un país que flotaba sobre un río azulado...Miré al cielo indolentemente y vi que todas las estrellas telegrafiaban en el infinito de sus parpadeos luminosos. Sirio sobre todas ellas enviaba tics anaranjados y tacs verdes entre el asombro de todas las demás. El telégrafo luminoso del cielo se unió al telégrafo pobre de la estación y mi alma (demasiado tierna) contestó con sus párpados a todas las preguntas y requiebros de las estrellas que entonces comprendí perfectamente. (O.C., 665)

En este caso, el objetivo de la actividad es lograr un desarrollo más extenso de las metáforas, dejarse llevar por la identificación con todas sus consecuencias y continuarla en un texto largo; además, al tratarse de prosa poética, puede ser más fácil para los estudiantes que la creación poética en verso, guiándose por ese tono surrealista tan próximo a la escritura autómatica. Se les pide concretamente que elijan la metáfora, de todas las que han creado durante las actividades anteriores, que les parezca más sugerente y redacten un texto en prosa donde las imágenes se vayan extendiendo, contagiando, como las ondas de una piedra caída en el estanque.

He seleccionado los tres mejores ejemplos, que, de hecho, me han sorprendido por su creatividad, de los textos resultantes en las aulas de la Facultad de Educación:

A toda prisa, la luna se sumergió en el río para lavarse la cara. Cuando terminó, se secó con la hierba de las orillas.

Se pintó la cara con la luz anaranjada del cielo. Se peinó con los cálidos vientos del sur. Como cada noche, se puso su vestido negro lleno de lunares resplandecientes. Ya estaba lista.

Salió nerviosa de casa, le temblaba todo el cuerpo. En el camino se encontró con el sol, que cansado, se iba a dormir.

(Elena Almodóvar)

Tic naranja

Tic amarillo

Tic colorado

Largo, corto, largo.... (¿Qué dirá la estrella?)

¿Quién mandará este mensaje? A lo mejor es reflejo de un espejo... Busco respuestas y por eso las encuentro.

Así que ¿Cuál era la pregunta?

(Beatriz Bautés)

El niño del perro color canela miró al cielo y preguntó a su padre:

- Papá ¿de qué están hechas las estrellas?

Su padre, viendo su carita inocente le contó una pequeña historia: 
- Las estrellas, hijo, están hechas de luna. Hace mucho tiempo, el Sol y la Luna eran amigos. Pero un día se pelearon y el Sol se enfadó tanto que decidió salir sólo cuando la Luna no saliese. La Luna se quedó muy triste... y, por eso, todas las noches, llora estrellas.

( Elena González)

También se han realizado actividades de creación de metáforas en las aulas de Primaria, en el Colegio El Cantizal. Se ha comenzado por preguntar a los niños que les parecen las estrellas, qué se imaginan cuando miran el cielo estrellado; estos son solo algunos de los resultados escogidos:

"Las estrellas son hombrecitos crucificados" (Mario, 8 años, $3^{\circ}$ de Primaria

"Los castaños florecen con estrellas blancas" (Simón, 11 años, $5^{\circ}$ de Primaria)

"Las estrellas son meteoritos que han chocado" (Pau, 11 años, $5^{\circ}$ de Primaria)

"Las estrellas son las flores de la noche"

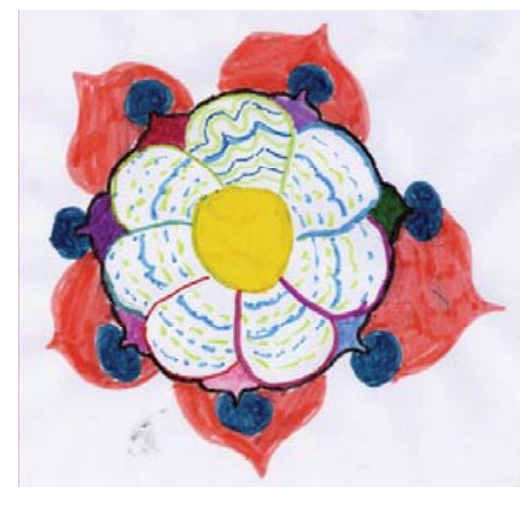
(Ilustración de Mar, 11 años, $5^{\circ}$ de Primaria)

Coincide así esta última imagen infantil con una de las metáforas lorquianas del Primer romancero gitano, en la que también se identifican las estrellas con distintos tipos de flores:

Las estrellas de la noche se volvieron campanillas $(\ldots)$

Las estrellas de la noche

Se volvieron siemprevivas (O.C., 432-33)

El proyecto de escritura creativa, aunque aquí nos centremos en las metáforas lorquianas como modelo, es mucho más extenso. Otras de las actividades diseñadas ${ }^{9}$ se han basado, por ejemplo, en el poema de José Agustín Goytisolo "Érase una vez un mundo al revés", así como en numerosos textos en prosa. En los cuentos de Julio Cortazar, concretamente, en las "Instrucciones para subir una escalera", que son tan interesantes para profundizar en el punto de vista literario, la mirada del narrador que no conoce el mundo que le rodea, mirada, por cierto, muy similar a la de los niños.

${ }^{9}$ Si se quieren consultar las otras experiencias de escritura creativa con distintos modelos literarios, remitimos a Educación literaria y escritura creativa (García Carcedo, 2011: p. 150 y stes.) 
Así que, aunque aquí no hayamos expuesto todas las experiencias, las tenemos en cuenta a la hora de redactar las conclusiones finales.

\section{CONCLUSIONES}

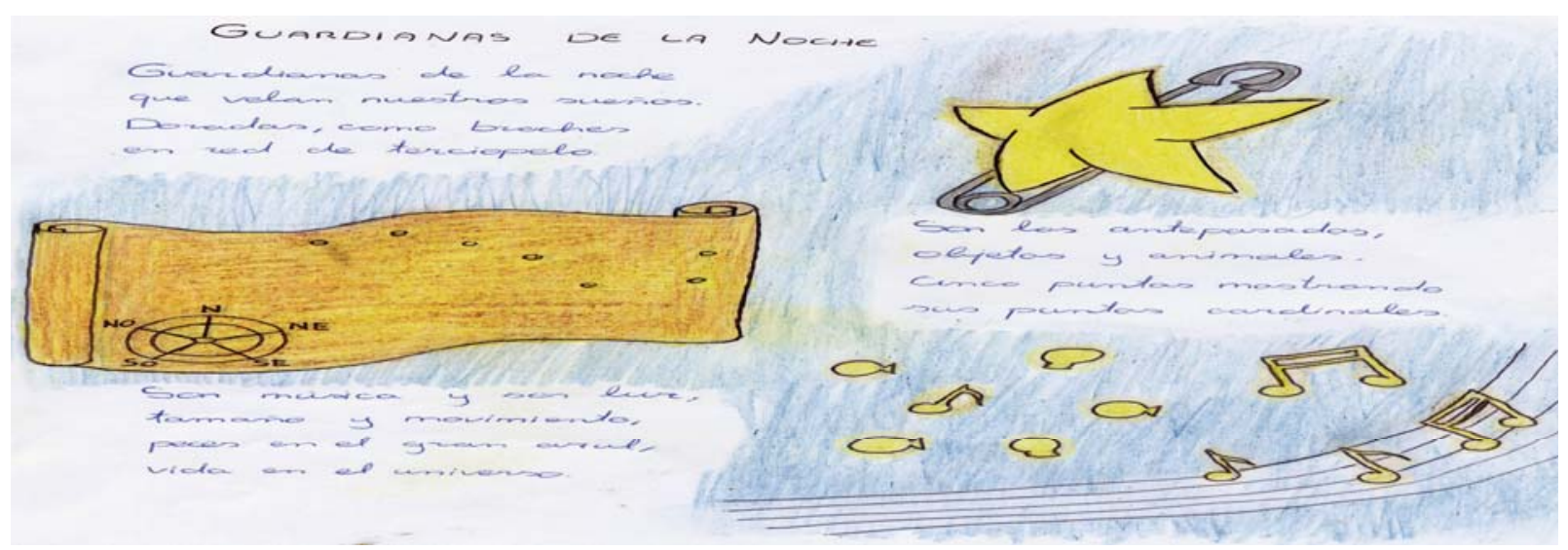

(“Guardianas de la noche", por Luis A. Fez)

Como advertíamos al comienzo, este artículo se ha estructurado en torno a dos partes bien diferenciadas. En primer lugar, un análisis exhaustivo de los versos metafóricos relacionados con las estrellas en la obras de Federico García Lorca; y, en segundo lugar, sugerencias y experiencias con actividades de creación de metáforas en las aulas tanto de la Facultad de Educación como de Educación Primaria.

La literatura ha estado siempre marcada por la intertextualidad y la complicidad con los textos precedentes, porque todo texto está construido a partir de obras anteriores y de la interiorización de los recursos utilizados por otros autores. Por eso este artículo ha partido de Lorca para profundizar en uno de los mecanismos estilísticos más productivos, que debería aprender a utilizar cualquiera que empiece a escribir.

Hemos visto que Lorca se aleja de las metáforas tradicionales para entrar en el ámbito del irracionalismo contemporáneo $\mathrm{y}$, con su impresionismo, nos conduce a sentir que la verdadera realidad de un objeto no está en el objeto mismo sino en la impresión que le causa al poeta. Nuestro modelo en la creación de metáforas casi nunca utiliza, por ejemplo, la comparación típica a la que hacía referencia Borges entre estrellas y ojos; sus metáforas son mucho más originales y los términos figurados con los que se relacionan los luceros son enormemente variados. Sólo en tres ocasiones encontramos la tan manida identificación entre estrellas y ojos, uno de los ámbitos semánticos con los que más aparecen identificadas las estrellas lorquianas es el del agua en todas sus variantes (surtidores, cauces, ríos etc. ).

Asimismo hemos podido comprobar que las metáforas de estrellas están mucho más presentes en las primeras obras que en las últimas. En todo Poeta en Nueva York , por ejemplo, no hay más que cinco casos, mientras que en Suites son veintisiete las ocasiones en que Lorca juega con las estrellas en sus metáforas. En cuanto a los términos figurados con los que Lorca realiza las identificaciones, es muy frecuente 
que se trate de elementos negativos, violentos o que transmiten desasosiego (espuelas, espadas, pulpos, etc.) Su vasto imaginario, sin embargo, alterna la identificación negativa de las estrellas con otros elementos de gran hermosura y sutileza. Hemos destacado esa dualidad variable como uno de los mayores logros de la poesía de Lorca, por el que las imágenes y las metáforas nunca pierden fuerza ni dejan de chocar al lector.

Tras esa revisión exhaustiva de los ejemplos lorquianos, hemos pasado a describir brevemente las experiencias de escritura creativa que hemos realizado, tanto libres como partiendo de la transformación de textos. La secuencia didáctica que hemos expuesto en estas páginas ha partido siempre de la lectura y análisis de una serie de versos de Lorca como textos de referencia. Hemos presentado una selección de las actividades y de los resultados de mayor calidad de las diferentes actividades creativas que se han realizado en las aulas, a partir de tres textos lorquianos, dos poemas y una prosa poética.

Solo queremos añadir, para terminar, que las experiencias han sido muy positivas y alentadoras y que nos parece imprescindible que aumente la presencia de la escritura creativa en los currículos de todos los niveles educativos. Hacer que los alumnos se dejen llevar por la intuición y se diviertan con las palabras, dar rienda suelta a la imaginación en las aulas y en la vida es una manera de liberar el encorsetado y a veces anacrónico sistema escolar. Intentemos que la sorpresa les despierte y las palabras más inesperadas se encuentren, como en este fragmento lorquiano de tan significativo título:

"Recreo del niño loco y el pájaro sin nido"

(Defínase con una imagen el punto de unión o el choque entre el surtidor del grillo y la liana de la estrella.)

(Lorca, O.C, 675)

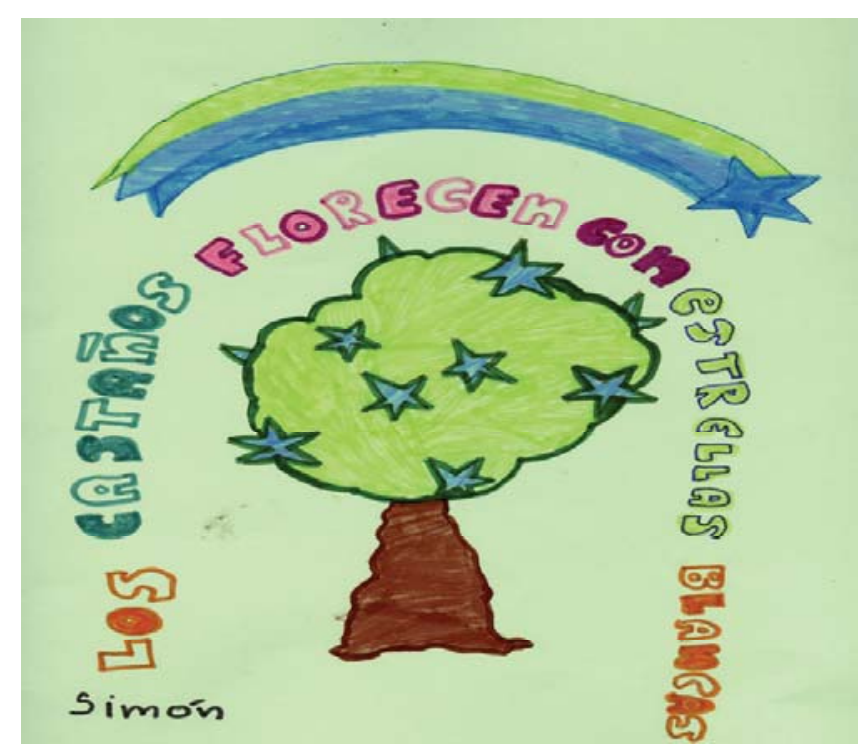

(Ilustración de Simón, $5^{\circ}$ de Primaria) 


\section{REFERENCIAS BIBLIOGRÁFICAS}

BOUSOÑO, Carlos (1985): Teoría de la expresión poética, Madrid, Gredos

DUCHESNE, A y LEGUAY,. T. (1984): Petite fabrique de littérature, Magnard, col. Textos y contextos.

GARCÍA CARCEDO, Pilar (ed.) (2008): Enseñanza virtual y presencial de las literaturas, Granada, Grupo Editorial Universitario. (2011): Educación literaria y escritura creativa, Granada, GEU.

GARCÍA LORCA, Federico (1996): Obras Completas I. Poesía, Barcelona, Círculo de Lectores.

GARDNER, J. (2001): El arte de la ficción, Madrid, Ediciones y talleres de escritura creativa Fuentetaja.

GARCÍA MONTERO, Luis (2000): Lecciones de poesía para niños inquietos, Granada, Comares.

JIMÉNEZ, Juan Ramón (1959): Libros de poesía, Madrid, Aguilar

MARINA, J.A. y VÁLGOMA, Ma DE LA (2007): La magia de escribir, Barcelona, Plaza y Janés.

MORENO, Victor (1995): Taller de cuentos, Pamplona, Gobierno de Navarra

MENDOZA FILLOLA, Antonio (2003): Didáctica de la Lengua y la Literatura, Madrid, Pearson Educación

NERUDA, Pablo (2005): Obras completas, Barcelona, RBA Círculo de Lectores

ORTEGA, Esperanza (1986): El baúl volador, Junta de Castilla y León .

PENNAC, Daniel (2003): Como una novela, Barcelona, Anagrama.

QUENEAU, Raymond (1987): Ejercicios de estilo, Madrid, Cátedra, $2^{\mathrm{a}}$ edición

RODARI, Gianni (2002): Gramática de la fantasía. Introducción al arte de contar historias, Barcelona, Planeta

TIMBAL-DUCLAUX, Louis (2004): Escritura creativa. Técnicas para liberar la inspiración y métodos de redacción, Madrid, Edad. 